\title{
Computational Fluid Dynamic Design and Experimental Study of a Temperature Sensor Array Used in Climate Reference Station
}

\author{
JIE YANG AND QINGQUAN LIU \\ Jiangsu Key Laboratory of Meteorological Observation and Information Processing, and Jiangsu Collaborative \\ Innovation Center on Atmospheric Environment and Equipment Technology, Nanjing University of \\ Information Science and Technology, Nanjing, China \\ WEI DAI \\ Key Laboratory of MEMS, Ministry of Education, Southeast University, Nanjing, China
}

(Manuscript received 21 February 2019, in final form 12 July 2019)

\begin{abstract}
Accurate air temperature measurements are demanded for climate change research. However, air temperature sensors installed in a screen or a radiation shield have traditionally resisted observation accuracy due to a number of factors, particularly solar radiation. Here we present a novel temperature sensor array to improve the air temperature observation accuracy. To obtain an optimum design of the sensor array, we perform a series of analyses of the sensor array with various structures based on a computational fluid dynamics (CFD) method. Then the CFD method is applied to obtain quantitative radiation errors of the optimum temperature sensor array. For further improving the measurement accuracy of the sensor array, an artificial neural network model is developed to learn the relationship between the radiation error and environment variables. To assess the extent to which the actual performance adheres to the theoretical CFD model and the neural network model, air temperature observation experiments are conducted. An aspirated temperature measurement platform with a forced airflow rate up to $20 \mathrm{~m} \mathrm{~s}^{-1}$ served as an air temperature reference. The average radiation errors of a temperature sensor equipped with a naturally ventilated radiation shield and a temperature sensor installed in a screen are $0.42^{\circ}$ and $0.23^{\circ} \mathrm{C}$, respectively. By contrast, the mean radiation error of the temperature sensor array is approximately $0.03^{\circ} \mathrm{C}$. The mean absolute error (MAE) between the radiation errors provided by the experiments and the radiation errors given by the neural network model is $0.007^{\circ} \mathrm{C}$, and the root-mean-square error (RMSE) is $0.009^{\circ} \mathrm{C}$.
\end{abstract}

\section{Introduction}

In the last few decades, climate change, especially global warming, has received wide attention from governments and general public throughout the world. The Intergovernmental Panel on Climate Change (IPCC) indicated that the global-averaged surface temperature has been increased over the twentieth century by about $0.6^{\circ} \mathrm{C}$ (https://www.ipcc.ch/report/ar5/wg3/). A special report on global warming of $1.5^{\circ} \mathrm{C}$ was approved by the IPCC on 8 October 2018 in Korea. One of the key messages that comes out very strongly from this report is that limiting global warming to $1.5^{\circ} \mathrm{C}$ could go hand in hand with ensuring a more sustainable and equitable society (https://www.ipcc.ch/sr15/). In recent years,

\footnotetext{
Corresponding author: Qingquan Liu, 001980@nuist.edu.cn
}

many research efforts have been focused upon the surface air temperature. The global-mean surface air temperature rose at a rate of $0.14^{\circ} \pm 0.06^{\circ} \mathrm{C}(\text { decade })^{-1}$ over the past 20 years (1993-2012) (Fyfe et al. 2013). Dillon researched the data of 3186 weather stations throughout the world in the period 1961-2009. The results show that the surface air temperature in tropical areas increased $0.4^{\circ} \mathrm{C}$, and the surface air temperature in the Northern Hemisphere areas increased $0.95^{\circ} \mathrm{C}$ (Dillon et al. 2010). Gleisner analyzed the data in the period 1979-2013, and concluded that the surface air temperature increased approximately $0.8^{\circ} \mathrm{C}$ (Gleisner et al. 2015). The surface air temperature change is on the order of $0.01^{\circ} \mathrm{C} \mathrm{yr}^{-1}$. Hence, the observation accuracy of the surface air temperature on the order of or less than $0.01^{\circ} \mathrm{C}$ would be desired.

Surface air temperature observation error consists of systematic error and radiation error. To reduce the 
systematic error induced by circuitry system, we designed a high-accuracy circuitry system based on potentiometer bridge. In addition, to reduce the systematic error caused by calibration, a 1595A superthermometer from Fluke and some fixed points of International Temperature Scale of 1990 (ITS-90) (Preston-Thomas 1990) are used to calibrate the temperature sensor. The accuracy of the $1595 \mathrm{~A}$ superthermometer and the temperature stability of the fixed points are $\pm 0.000015^{\circ}$ and $\pm 0.0002^{\circ} \mathrm{C}$, respectively. Hence, the magnitude of the systematic error may be able to reach the order of $0.01^{\circ} \mathrm{C}$. By contrast, the magnitude of the radiation error is much larger than that of the systematic error. A number research papers show that the magnitude of the error caused by solar radiation is on the order of $1^{\circ} \mathrm{C}$ (Lopardo et al. 2014; Holden et al. 2013; Lin et al. 2001a). To reduce the radiation error, a temperature sensor needs to be housed in a radiation shield or a screen, which are capable of blocking a large proportion of direct and reflected solar radiation. However, the radiation shield or the screen will reduce the airflow rate near the temperature sensor, which will uncouple the sensor from the air whose temperature it is meant to measure (Harrison 2011; Harrison and Wood 2012).

A number of studies have been drawn to investigating the performance of screens and radiation shields (Anderson and Baumgartner 1998; Hubbard et al. 2001; van der Meulen and Brandsma 2008; Mozny et al. 2012). A number of factors, particularly wind (Lin et al. 2001b), radiation (Lin et al. 2001b), coating (Lopardo et al. 2014), and underlying surface (Lin et al. 2005) displayed remarkable impacts on the radiation error of the temperature sensor. In addition, to improve protection from direct radiation and reflected radiation, a variety of radiation shields with different structures have been designed and evaluated. Erell proposed some new radiation shields, and performed a series of comparative measurements to evaluate them. The results indicated that the mean temperature recorded in the Stevenson screen was lower than that recorded in all the new radiation shields, with a difference up to $0.8^{\circ} \mathrm{C}$ (Erell et al. 2005). Hubbart designed a new radiation shield, and evaluated it under cloudless conditions. A Gill aspirated device serves as an air temperature reference. The results indicated that the mean radiation error of the new radiation shield was $2.84^{\circ} \mathrm{C}$ (Hubbart 2011).

The flowing air can reduce the radiation error by facilitating the diffusion of radiant heat. Therefore, the use of aspirated device has become prevalent due to the technical advantages afforded. Many research efforts have been focused upon the performance of aspirated devices (Georges and Kaser 2002; Mahajan et al. 2005; Thomas and Smoot 2013). The R. M. Young Company designed an aspirated device, model 43502. The forced airflow rate of the model 43502 shield ranges from 5 to $11 \mathrm{~m} \mathrm{~s}^{-1}$. When the force airflow rate and the solar radiation intensity are $11 \mathrm{~m} \mathrm{~s}^{-1}$ and $1000 \mathrm{~W} \mathrm{~m}^{-2}$, respectively, the radiation error of the 43502 shield is $0.2^{\circ} \mathrm{C}$. Thomas and Smoot designed an aspirated radiation shield and performed a series of measurements to evaluate it. The results indicated that the radiation error is approximately $0.2^{\circ} \mathrm{C}$ (Thomas and Smoot 2013). If a radiation error of $0.1^{\circ} \mathrm{C}$ or even lower is desired, further increase of the force airflow rate inside the aspirated device is necessary. To achieve higher force airflow rate, an air pump with a relatively high power is needed. However, it was recognized that the power requirement and reliability of such systems present a major limitation for the applications of the aspirated device.

This paper presents a temperature sensor array, which contains seven tube-shaped radiation shields, seven platinum resistance temperature sensors, an aluminum plate with a silver mirror surface, a wooden heat shield, and a high-accuracy temperature measurement module. The temperature sensor array has multiple portals so that at least one will always face directly into the wind and so receive full ventilation from natural wind flow, regardless of wind direction. Because the radiation error diminishes with increasing airflow rate, and diminishes with decreasing heat pollution, the radiation error of the sensor face to the wind direction is minimal. During daytime, due to solar radiation effect, the observed air temperature is greater than the actual free air temperature. However, due to longwave radiation effect, the observed air temperature should be lower than the actual free-air temperature during nighttime. Because the longwave radiation error during nighttime is smaller than the solar radiation error during daytime, we start this research by focusing on the relatively large radiation error during daytime. To verify the actual performance of the temperature sensor array, experiments were performed.

\section{Computational fluid dynamics design of the temperature sensor array}

\section{a. Computational fluid dynamics model construction}

The temperature sensor array consists of seven tubeshaped radiation shields. Each of the seven shields encloses a platinum resistance temperature sensor. An aluminum plate with a silver mirror surface and a wooden heat shield are placed on the top. The platinum resistance temperature sensor is located on the axis of symmetry. To decrease the error induced by direct solar radiation and reflected solar radiation, a 


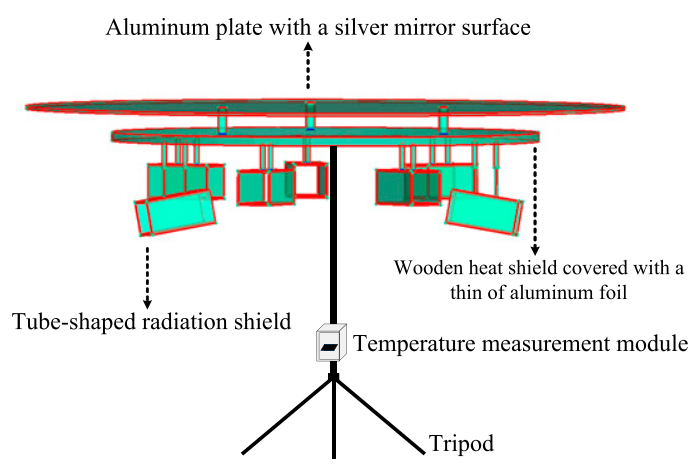

(a)

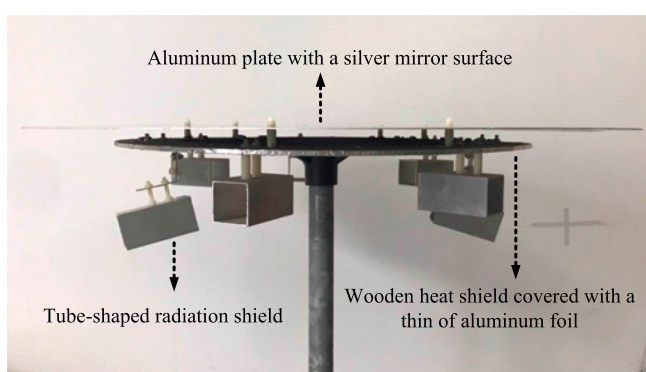

(b)

FIG. 1. A 3D sketch of the temperature sensor array.

4270 AG aluminum plate manufactured by Alanod Company is installed above the temperature sensors. The diameter, thickness, and reflectivity of the aluminum plate are $700 \mathrm{~mm}, 2 \mathrm{~mm}$, and $95 \%$, respectively. The wooden heat shield covered with a thin of aluminum foil is installed between the aluminum plate and the sensors. The heated air surrounding the aluminum plate induced by solar radiation is blocked by the wooden heat shield to reach the locations, where the sensors are installed. The diameter, thickness, and reflectivity of the wooden heat shield are $500 \mathrm{~mm}, 10 \mathrm{~mm}$, and $87 \%$, respectively. Seven tube-shaped shields with different orientation are designed for the seven sensors. To reduce heat conduction between the sensor probes and the walls of the tube-shaped shields, a lead encapsulation layer is made by a type of low-thermal-conductivity material, which can prevent the radiant heat pollution from the shields, when supplying mechanical support. The temperature measurement module houses a lownoise, high-accuracy electronic circuit (Fig. 1).

The angle between the wind direction and due east is $\alpha$. The angle between adjacent tube-shaped radiation shields is $\beta$. Each of the radiation shields possesses different ventilation when $\alpha$ is fixed. Since the radiation error decreases with the increase of airflow rate, the minimum error appears at a sensor inside the tubeshaped shield with the maximum airflow rate. Because all of the platinum resistance temperature sensor are calibrated by using the fixed points of ITS-90 and a $1595 \mathrm{~A}$ superthermometer, and because the thermometer circuit can achieve up to 1-10-ppm repeatability under typical outdoor environment, this minimum error can be regarded as the radiation error of the entire array. The solar radiation may directly arrive at the sensor surface at sunrise and sunset if the tube-shaped radiation shields are horizontally installed. To prevent the sensor from directly illuminating, the tube-shaped radiation shield $m$ and shield $p$ tilt down $10^{\circ}$ in this design. The rest of the tube-shaped radiation shields are horizontally installed (Fig. 2).

A technology of unstructured mesh from a computational fluid dynamics (CFD) software ICEM is used to generate a tetrahedral mesh of the temperature sensor array. Although large size of air domain is beneficial to

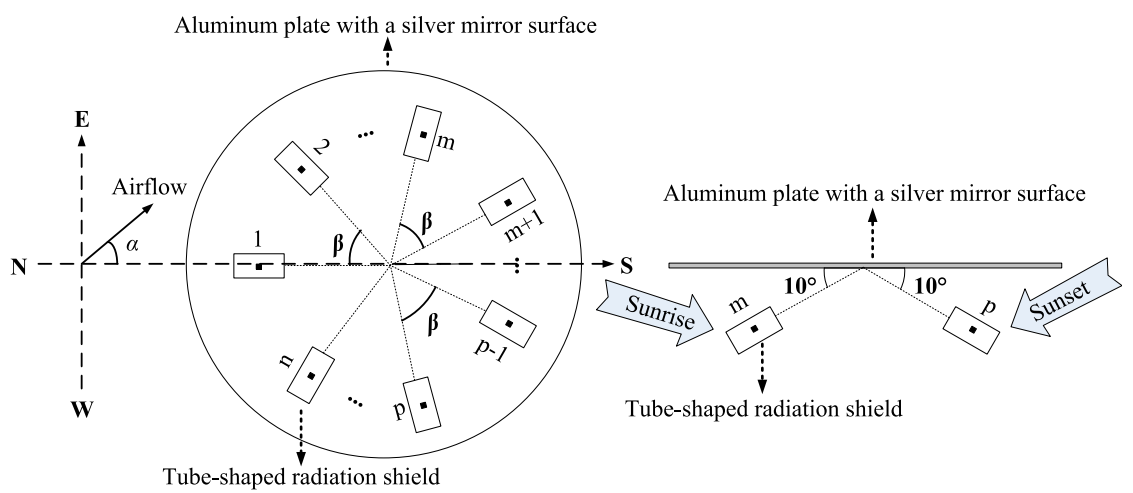

FIG. 2. Schematic of (left) top view of the tube-shaped radiation shields and (right) side view of the tilting radiation shields. 

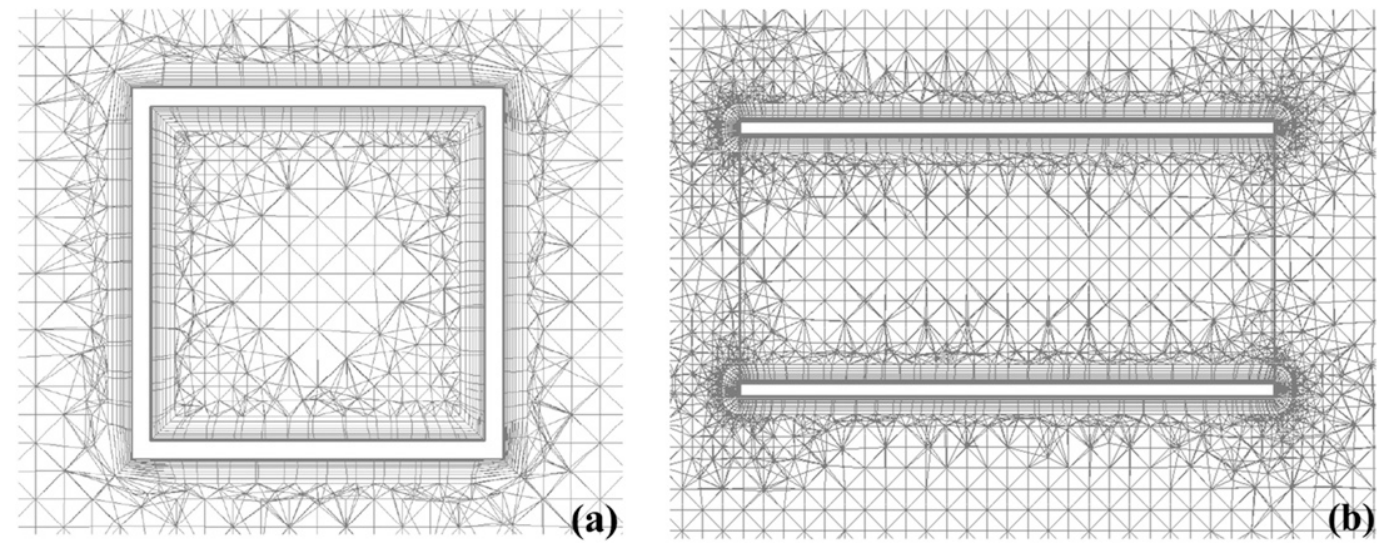

FIG. 3. Mesh refinement. (a) Top view and (b) side view of a tube-shaped radiation shield.

improve the numerical solution accuracy, it also leads to computation complexity. It is concluded that the reasonable air domain size is $3500 \mathrm{~mm} \times 3000 \mathrm{~mm} \times$ $7000 \mathrm{~mm}$ by comparing models with a variety of air domains. To model the heat exchange between fluid and solid, a boundary layer grid for the interface of fluid and solid is designed. The quality of the grid is greater than 0.3 (Fig. 3). Then a CFD software Fluent is adopted to simulate the mesh model of the temperature sensor array (Tang et al. 2017). To improve the accuracy of simulation results, a standard initialization method, a standard Semi-Implicit Method for Pressure-Linked Equations (SIMPLE) algorithm, a $k-\varepsilon$ model (Kumar and Kim 2016), and a solar ray tracing model (Wang et al. 2010) are employed in the numerical computation. In addition, a second-order upwind method is used to solve the turbulence, energy and momentum parameters (Sarhan et al. 2017). Boundary conditions are set according to the physical environment to assure the validity of the simulation results. The materials properties of the temperature sensor array are listed in Table 1. The values listed in Table 1 are given by a material database of the CFD software Fluent.

\section{b. Design optimization}

To make sure that at least one tube-shaped shield is supplied with relatively good ventilation under any wind direction, wind velocity, and temperature fields of the temperature sensor array models with different $\beta$ are numerically solved. The velocity and temperature fields are shown in Fig. 4.

In the models, the ambient wind speed, solar radiation intensity, diffuse solar irradiation, reflectivity of the underlying surface, altitude, and sun elevation angle are $2 \mathrm{~m} \mathrm{~s}^{-1}, 1000 \mathrm{~W} \mathrm{~m}^{-2}, 200 \mathrm{~W} \mathrm{~m}^{-2}, 20 \%, 0 \mathrm{~km}$, and $45^{\circ}$, respectively. The CFD results show that the airflow rates at the center point of a tube-shaped shield with a $\beta$ of $10^{\circ}, 30^{\circ}, 60^{\circ}$, and $90^{\circ}$ are $1.97,1.99,1.81$, and $0.79 \mathrm{~m} \mathrm{~s}^{-1}$ respectively. The radiation errors are $0.04^{\circ}, 0.05^{\circ}, 0.17^{\circ}$, and $0.58^{\circ} \mathrm{C}$, respectively. When $\beta$ is less than a certain angle, the heated air flows along the tube-shaped shield wall and generally form a laminar flow, which does not affect the center point of the tube-shaped shield, where the probe is located. With a relatively large $\beta$, the heated air may diffuse to the center location of the tube-shaped shield from the wall and then heats the sensor. This phenomenon is called heat pollution.

It can be inferred that the heat pollution reduces with decreasing the value of $\beta$. To minimize the heat pollution as much as possible, the CFD method is applied to calculate the radiation errors of the temperature sensor array models with different $\beta$, while the ambient wind speed, solar radiation intensity, diffuse solar irradiation, reflectivity of the underlying surface, altitude, and sun elevation angle are $2 \mathrm{~m} \mathrm{~s}^{-1}, 1000 \mathrm{~W} \mathrm{~m}^{-2}, 200 \mathrm{~W} \mathrm{~m}^{-2}$, $20 \%, 0 \mathrm{~km}$, and $45^{\circ}$, respectively.

When $\beta$ is $10^{\circ}, 20^{\circ}, 30^{\circ}, 45^{\circ}, 52^{\circ}$, and $60^{\circ}$, the number of tube-shaped shields is $36,18,12,8,7$, and 6 , respectively. The radiation error of the temperature sensor array is less than $0.1^{\circ} \mathrm{C}$ when $\beta$ is less than $52^{\circ}$. The radiation error increases rapidly when $\beta$ is larger than $52^{\circ}$ (Fig. 5). To maintain a small radiation error, $\beta$ must be smaller than or equal to $52^{\circ}$, which sets a lower limit of 7 on the number of tube-shaped shields. Further increase of the number of tube-shaped shields can reduce

TABLE 1. Material properties of the temperature sensor array.

\begin{tabular}{lccc}
\hline \hline Material & $\begin{array}{c}\text { Density } \\
\left(\mathrm{kg} \mathrm{m}^{-3}\right)\end{array}$ & $\begin{array}{c}\text { Heat capacity } \\
\left(\mathrm{J} \mathrm{kg}^{-1} \mathrm{~K}^{-1}\right)\end{array}$ & $\begin{array}{c}\text { Thermal conductivity } \\
\left(\mathrm{W} \mathrm{m}^{-1} \mathrm{~K}^{-1}\right)\end{array}$ \\
\hline Aluminum & 2719 & 871 & 202.4 \\
Plastic & 110 & 1591 & 0.2 \\
Platinum & 21450 & 133 & 71.4 \\
Wood & 700 & 2310 & 0.173 \\
\hline
\end{tabular}



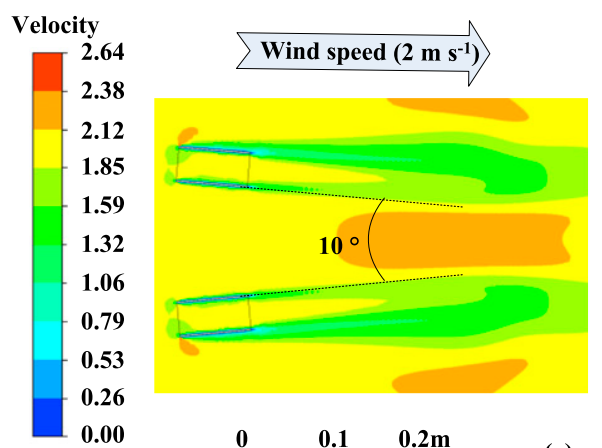

$\left[\mathrm{m} \mathrm{s}^{-1}\right]$
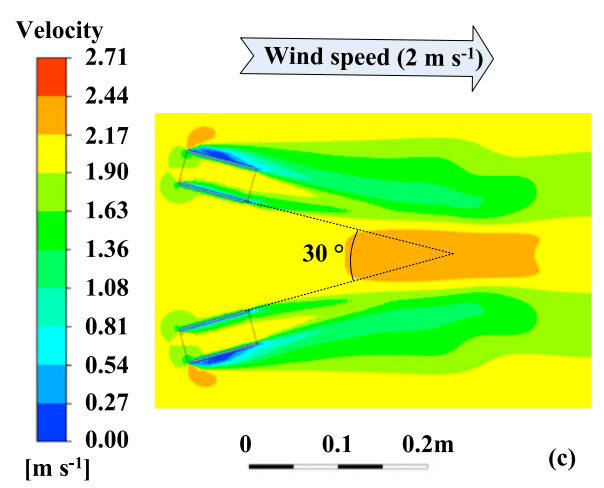

Velocity
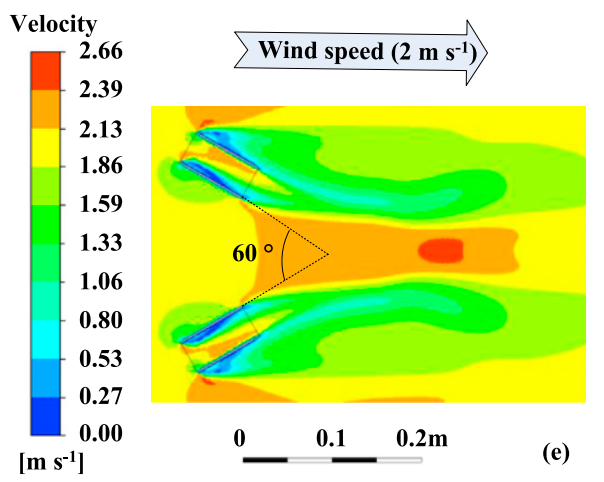

Velocity

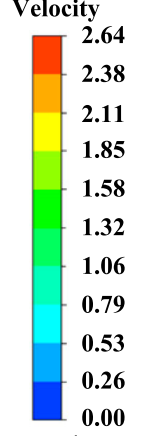

$\left[\mathrm{m} \mathrm{s}^{-1}\right]$

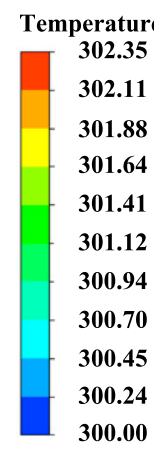

[K]
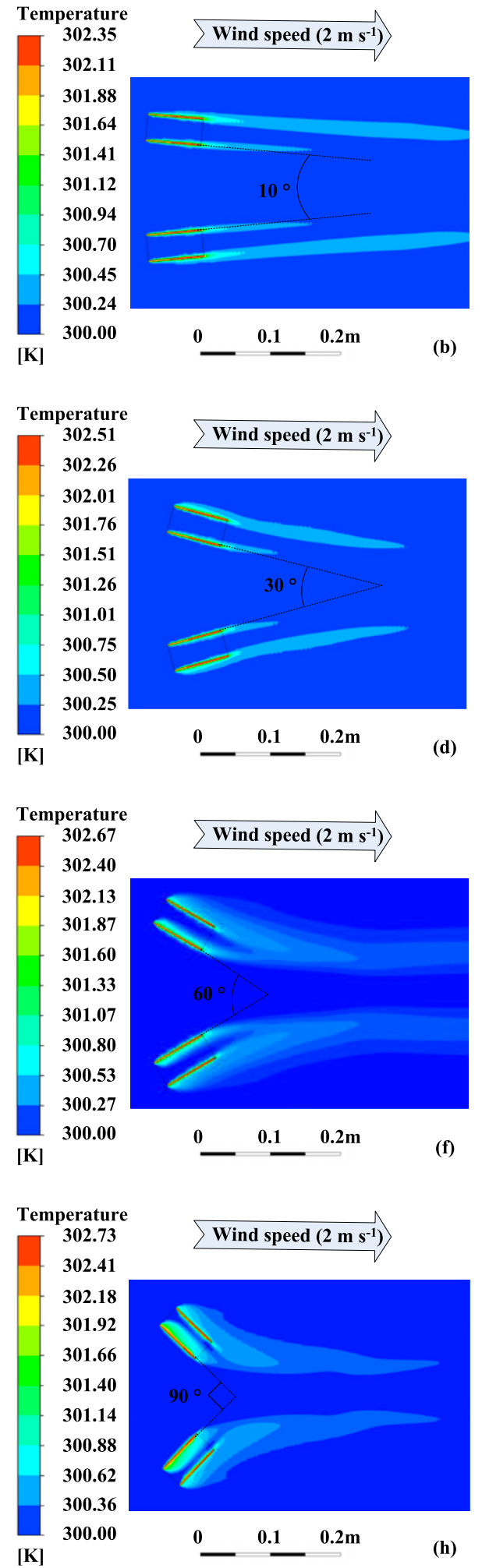

FIG. 4. Simulation results of the (left) velocity and (right) temperature fields under different values of $\beta$. 


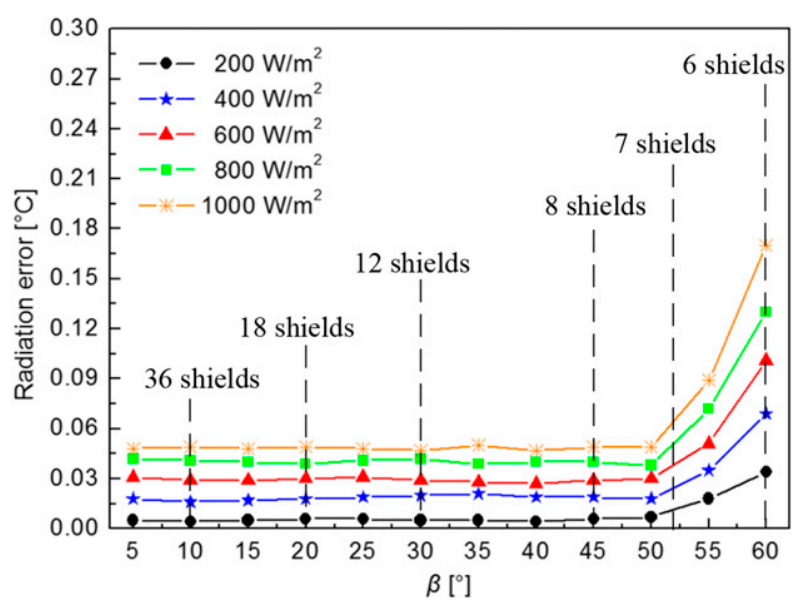

FIG. 5. The relationship among solar radiation intensity, radiation error, and $\beta$.

the radiation error marginally at the price of complexity and manufacturing cost.

\section{c. Comparison of temperature and velocity fields}

To compare the performance of the temperature sensor array, the temperature sensor equipped with a naturally ventilated radiation shield and the temperature sensor equipped with a screen, the CFD models of these instruments are calculated under an identical environment. The ambient wind speed is set to $2 \mathrm{~m} \mathrm{~s}^{-1}$, the solar radiation intensity is set to $1000 \mathrm{~W} \mathrm{~m}^{-2}$, the diffuse solar irradiation is set to $200 \mathrm{~W} \mathrm{~m}^{-2}$, the reflectivity of the underlying surface is set to $20 \%$, the altitude is set to $0 \mathrm{~km}$, and the sun elevation angle is set to $45^{\circ}$. The reflectivities of the coatings of the naturally ventilated radiation shield, the screen, the aluminum plate and the tube-shaped radiation shields are $87 \%, 87 \%, 95 \%$, and $85 \%$, respectively. The velocity and temperature fields are shown in Fig. 6.

The radiation error of the temperature sensor equipped with a screen is $0.54^{\circ} \mathrm{C}$ (Fig. 6a), and the radiation error of the sensor equipped with a naturally ventilated radiation shield is $0.72^{\circ} \mathrm{C}$ (Fig. 6c). In contrast, the simulation result of the temperature sensor array shows that the radiation errors of the sensors $1-7$ are $0.05^{\circ}, 1.81^{\circ}$, $2.79^{\circ}, 0.29^{\circ}, 0.68^{\circ}, 1.95^{\circ}$, and $0.31^{\circ} \mathrm{C}$, respectively. Hence, the radiation error of the temperature sensor array is $0.05^{\circ} \mathrm{C}$ (Fig. 6e). The airflow rate inside the screen decreases from 2 to $0.31 \mathrm{~m} \mathrm{~s}^{-1}$ (Fig. 6b), and the airflow rate inside the naturally ventilated radiation shield reduces from 2 to $0.34 \mathrm{~m} \mathrm{~s}^{-1}$ (Fig. 6d). While the airflow rates at the center point of tube-shaped shields $1-7$ are $1.77,0.63,0.06,1.70,0.87,0.21$, and $1.59 \mathrm{~m} \mathrm{~s}^{-1}$, respectively (Fig. 6f). The simulation results indicate that the temperature sensor array proposed in this paper may be able to improve the air temperature observation accuracy.

\section{d. Correction of radiation error}

To further improve the accuracy of the temperature sensor array, it is necessary to design a radiation error correction method for this sensor array. The correction method is based on the CFD method and a neural network method. The CFD method is implemented to obtain the radiation errors of the temperature sensor array under different conditions including solar radiation intensity, wind speed, sun elevation angle, reflectivity of the underlying surface, and altitude. The default values of the solar radiation intensity, diffuse solar irradiation, reflectivity of underlying surface, wind speed, sun elevation angle, and altitude are $1000 \mathrm{~W} \mathrm{~m}^{-2}, 200 \mathrm{~W} \mathrm{~m}^{-2}$, $0.2,0.5 \mathrm{~m} \mathrm{~s}^{-1}, 45^{\circ}$, and $0 \mathrm{~km}$, respectively. When the solar radiation intensity is $200-1000 \mathrm{~W} \mathrm{~m}^{-2}$, and the wind speed ranges from 0.5 to $10 \mathrm{~m} \mathrm{~s}^{-1}$, the radiation errors shown in Fig. $7 \mathrm{a}$ are obtained. While the range of the sun elevation angle is $10^{\circ}-90^{\circ}$, and the wind speed ranges from 0.5 to $10 \mathrm{~m} \mathrm{~s}^{-1}$, the radiation errors shown in Fig. $7 \mathrm{~b}$ are obtained. When the wind speed ranges from 0.5 to $10 \mathrm{~m} \mathrm{~s}^{-1}$, and the reflectivity of the underlying surface ranges from $10 \%$ to $90 \%$, the radiation errors shown in Fig. 7c are obtained. When the range of wind speed is $0.5-10 \mathrm{~m} \mathrm{~s}^{-1}$, and the altitude ranges from 0 to $5 \mathrm{~km}$, the radiation errors shown in Fig. $7 \mathrm{~d}$ are obtained.

As can be seen from the curved surface in Fig. 7, the radiation error decreases with decreasing solar radiation intensity, altitude, and reflectivity of the underlying surface. The radiation error also decreases with increased airflow rate. The radiation error is $0.05^{\circ} \mathrm{C}$, when the wind speed, solar radiation intensity, sun elevation angle, reflectivity of the underlying surface, and altitude are $0.5 \mathrm{~m} \mathrm{~s}^{-1}, 1000 \mathrm{~W} \mathrm{~m}^{-2}, 45^{\circ}, 20 \%$, and $0 \mathrm{~km}$, respectively. When the wind speed is greater than $2.5 \mathrm{~m} \mathrm{~s}^{-1}$, the radiation error may be reduced to $0.01^{\circ} \mathrm{C}$ (Fig. 7a). The radiation errors are $0.05^{\circ}, 0.06^{\circ}, 0.06^{\circ}$, $0.06^{\circ}, 0.06^{\circ}, 0.06^{\circ}, 0.06^{\circ}, 0.05^{\circ}$, and $0.04^{\circ} \mathrm{C}$ with the sun elevation angle changing from $10^{\circ}$ to $90^{\circ}$, when the wind speed, solar radiation intensity, reflectivity of the underlying surface, and altitude are $0.5 \mathrm{~m} \mathrm{~s}^{-1}, 1000 \mathrm{~W} \mathrm{~m}^{-2}$, $20 \%$, and $0 \mathrm{~km}$, respectively (Fig. $7 \mathrm{~b}$ ). The radiation errors are $0.04^{\circ}, 0.05^{\circ}, 0.06^{\circ}, 0.07^{\circ}$, and $0.07^{\circ} \mathrm{C}$ with the reflectivity of the underlying surface changing from $10 \%$ to $90 \%$, when the wind speed, solar radiation intensity, sun elevation angle, and altitude are $0.5 \mathrm{~m} \mathrm{~s}^{-1}$, $1000 \mathrm{~W} \mathrm{~m}^{-2}, 45^{\circ}$, and $0 \mathrm{~km}$, respectively (Fig. $7 \mathrm{c}$ ). Because the density of air decreases with the ascending altitude, and because thin air impedes the radiant heat dissipation, the altitude is an important factor for the 

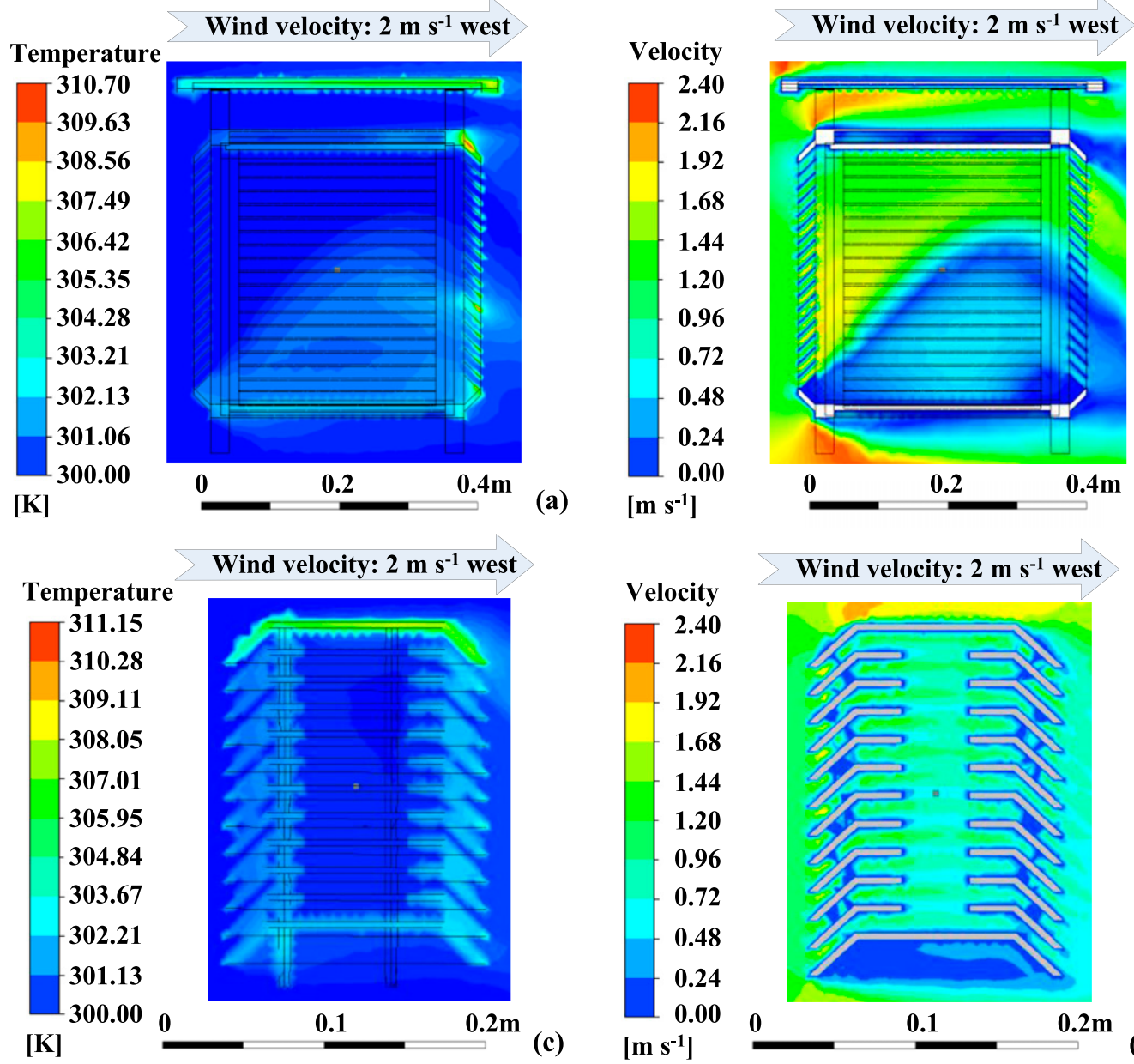

(a)

[m s s]

(b)

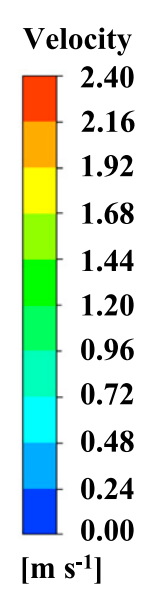

Wind velocity: $2 \mathrm{~m} \mathrm{~s}^{-1}$ west

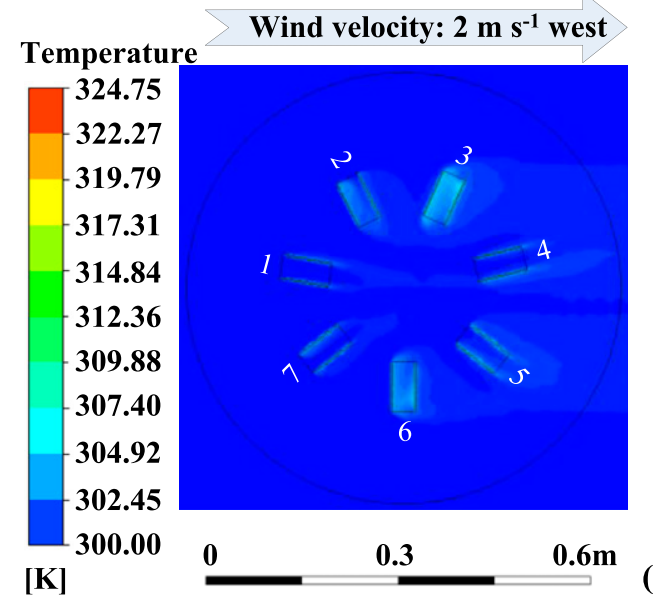

(c) $\quad\left[\mathrm{m} \mathrm{s}^{-1}\right]$
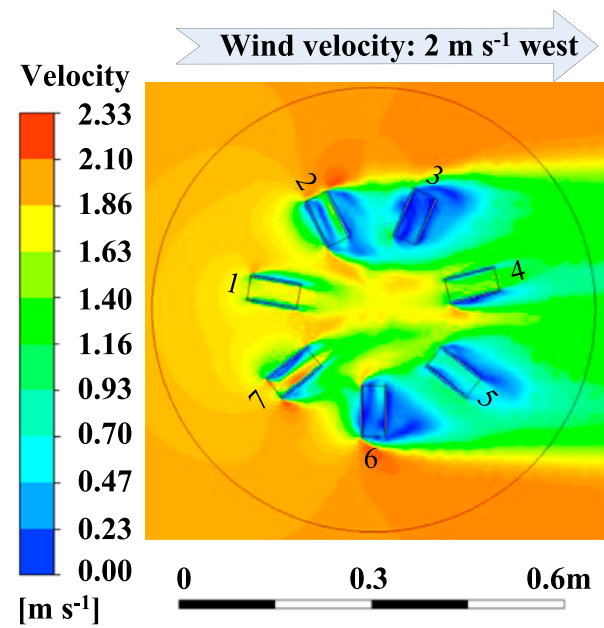

(f)

FIG. 6. Simulation results of the temperature and velocity fields. (a),(c),(e) Temperature and (b),(d),(f) velocity fields of (top) the temperature sensor probe equipped with a screen, (middle) the probe equipped with a naturally ventilated radiation shield, and (bottom) the temperature sensor array. 

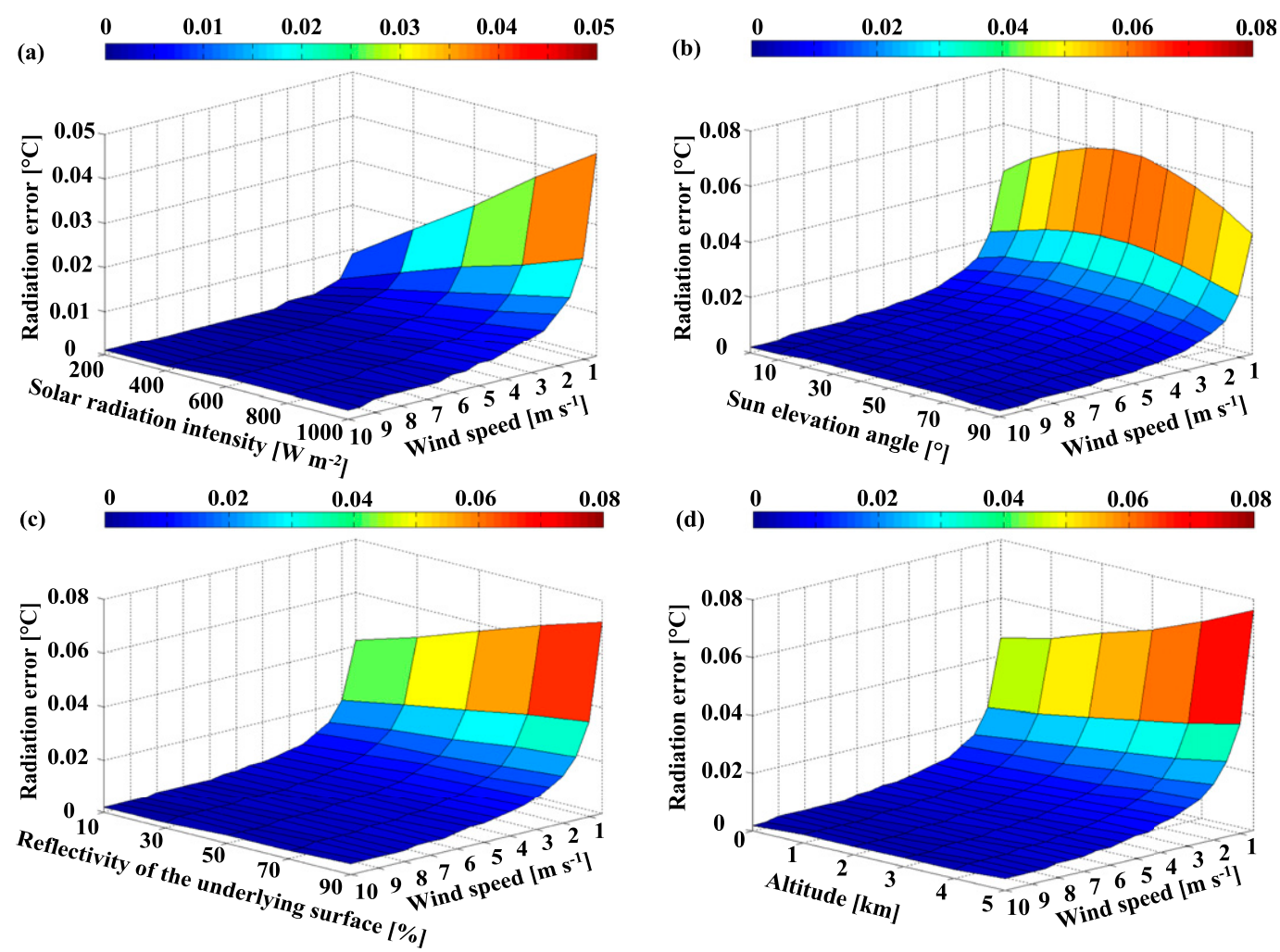

FIG. 7. The radiation errors calculated by the CFD method under the conditions of various wind speeds and various (a) solar radiation intensities, (b) sun elevation angles, (c) reflectivities of underlying surface, and (d) altitudes.

correction of radiation error. The radiation errors are $0.05^{\circ}, 0.05^{\circ}, 0.06^{\circ}, 0.06^{\circ}, 0.07^{\circ}$, and $0.08^{\circ} \mathrm{C}$ with the altitude changing from 0 to $5 \mathrm{~km}$, when the solar radiation intensity, wind speed, reflectivity of the underlying surface, and sun elevation angle are $1000 \mathrm{~W} \mathrm{~m}^{-2}, 0.5 \mathrm{~m} \mathrm{~s}^{-1}$, $20 \%$, and $45^{\circ}$, respectively (Fig. $7 \mathrm{~d}$ ).

To obtain the radiation error under any environmental condition, a radiation error correction equation may be needed. A neural network method is used to obtain the radiation error correction equation (Yang et al. 2018):

$$
\begin{aligned}
\Delta T= & \operatorname{purelin}\left\{\operatorname { t a n s i g } \left(V W_{1 i}+P W_{2 i}+E W_{3 i}\right.\right. \\
& \left.\left.+f W_{4 i}+A W_{5 i}+\theta_{i}\right) W_{k 1}+a_{k}\right\},
\end{aligned}
$$

where $V$ is the wind speed, $P$ is the solar radiation intensity, $E$ is the sun elevation angle, $f$ is the reflectivity of the underlying surface, and $A$ is the altitude. The subscripts are as follows: $j$ is the number of the input-layer neurons, $i$ is the number of the hidden-layer neurons, and $k$ is the number of the output-layer neurons. The value of $j$ is 3 , the value of $i$ is 5 , and the value of $k$ is 1 . The terms $W_{1 i}, W_{2 i}, W_{3 i}, W_{4 i}$, and $W_{5 i}$ are weights, which are from hidden layer to input layer, of $V, P, E, f$, and $A$, respectively. The term $W_{k 1}$ is a weight from output layer to hidden layer, $a_{k}$ is a threshold of output layer, and $\theta_{i}$ is a threshold of hidden layer.

The temperature sensor array is designed for important climate reference stations, which are generally well maintained. These stations contain the data required in the correction equation [Eq. (1)]. If embedding the correction equation [Eq. (1)] into a climate reference station is realized, the radiation error can be predicted by substituting the measurement results of the wind speed, solar radiation intensity, sun elevation angle, altitude, and reflectivity of the underlying surface into the correction equation [Eq. (1)], and then the air temperature observed results of the temperature sensor array can be modified.

\section{Experimental setup}

To verify the actual performance of the temperature sensor array, a number of observation experiments are implemented on sunny days at the Nanjing University of Information Science and Technology site $\left(32.12{ }^{\circ} \mathrm{N}\right.$, $118.42^{\circ} \mathrm{E}$, elevation: $22 \mathrm{~m}$ ). The temperature sensor array, a temperature sensor equipped with a naturally ventilated radiation shield, a temperature sensor equipped with a screen, and an aspirated temperature measurement platform are installed on a frame at a 
(a)

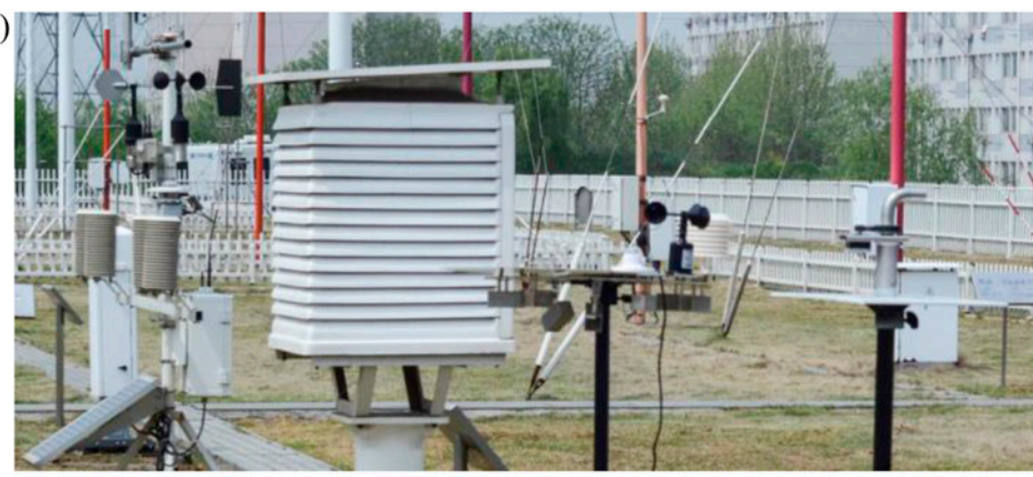

(b)

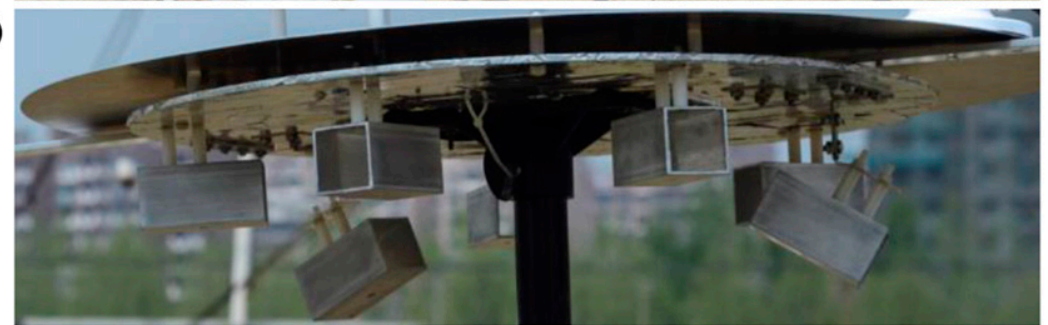

(c)

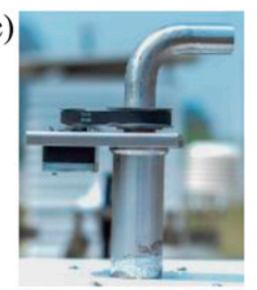

(d)

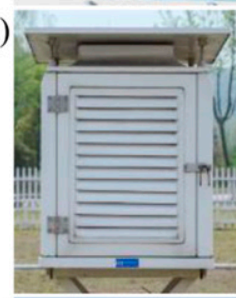

(e)

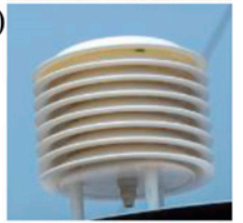

FIG. 8. Photos of experimental setup. (a) The entire the experimental field, (b) the temperature sensor array, (c) the aspirated temperature measurement platform, (d) the screen, and (e) the naturally ventilated radiation shield.

height of $1.5 \mathrm{~m}$ from grass underlying surface. The aspirated temperature measurement platform with the force airflow rate up to $20 \mathrm{~m} \mathrm{~s}^{-1}$ serves as an air temperature reference (Yang et al. 2016). The instruments are shown in Fig. 8.

\section{Results}

\section{a. Contrast observation in field}

A CMP21 Pyranometer from Kipp and Zonen and a 03002 wind sentry manufactured by the R. M. Young Company are used to measure the solar radiation intensity and the wind speed, respectively. The wind speed and solar radiation intensity observed results are shown in Fig. 9.

The experimental data are collected every $30 \mathrm{~min}$. Figure 10 compares the radiation errors of the temperature sensor equipped with a naturally ventilated radiation shield, the temperature sensor equipped with a screen, and the temperature sensor array.

The average radiation error of the temperature sensor installed in a naturally ventilated radiation shield is $0.42^{\circ} \mathrm{C}$, and the average radiation error of the temperature sensor installed in a screen is $0.23^{\circ} \mathrm{C}$. In contrast, the mean radiation error of the temperature sensor array is $0.03^{\circ} \mathrm{C}$ (Fig. 10). Hence, this instrument may block a large proportion of direct and reflected
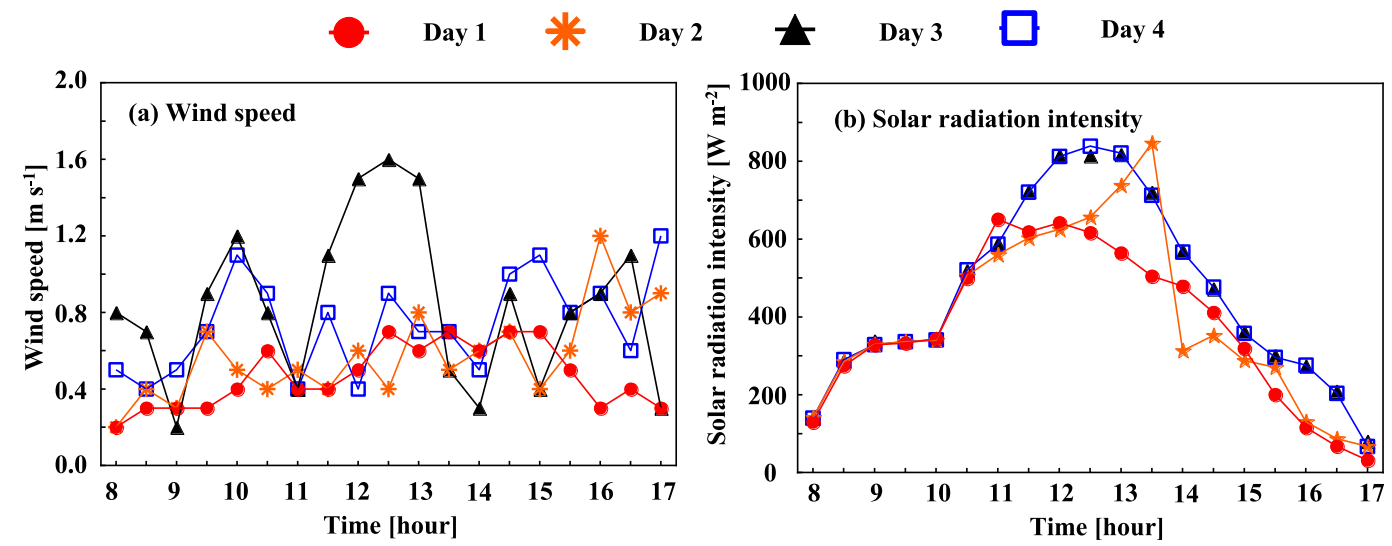

FIG. 9. Measurement results for (a) wind speed and (b) solar radiation intensity at different times. 


\section{Naturally ventilated radiation shield $\quad$ Thermometer screen $\quad \hat{Z}$ Temperature sensor array}
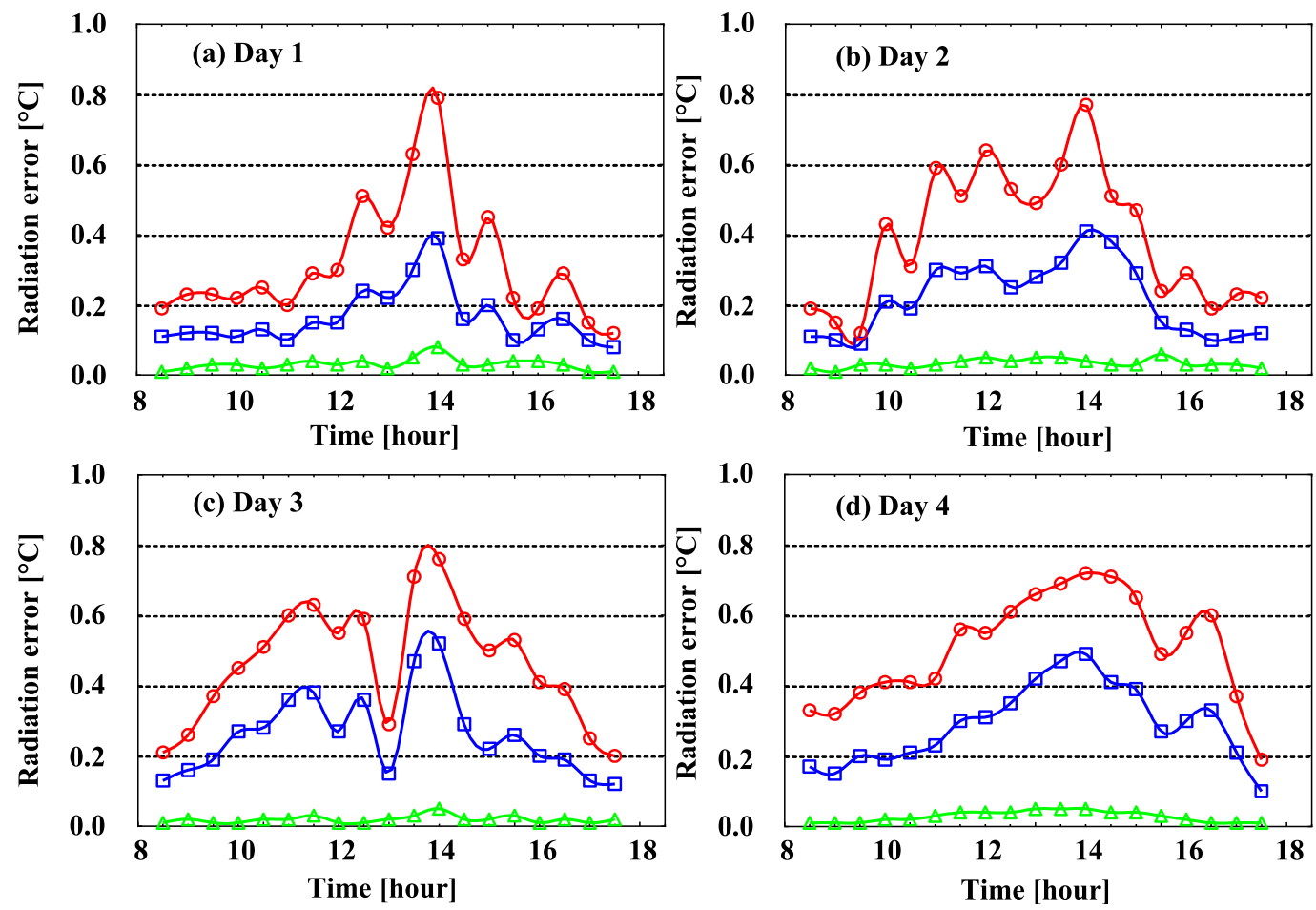

FIG. 10. Comparisons of radiation errors at different times.

solar radiation and provide a possibility of significant improvement of the air temperature observation accuracy.

\section{b. Analysis on experimental results and corrected results}

A number of comparisons between the experimental results and the corrected results have been performed to verify the efficiency of the correction equation [Eq. (1)]. The corrected radiation error results provided by Eq. (1) can be obtained by substituting the measured results of the wind speeds, the solar radiation intensities, the reflectivities of the underlying surface, the altitudes, and the sun elevation angles into Eq. (1). The radiation errors given by Eq. (1) and the radiation errors given by the comparison experiment with the air temperature reference are shown in Fig. 11.

Because the solar radiation intensity is at the highest level at noon, the radiation errors of the temperature sensor array are larger than that of the other times. Because the sun elevation angle is relatively small at sunrise and sunset, the solar radiation may directly arrive at the location, where the temperature sensor is installed. Therefore, if the wind speed at noon is much larger than the wind speed at sunrise or sunset, the radiation error at sunrise or sunset may be slightly larger than the radiation error at noon.

The mean radiation error given by Eq. (1) and the mean radiation error given by the comparison experiment with the air temperature reference are $0.02^{\circ}$ and $0.03^{\circ} \mathrm{C}$, respectively. A root-mean-square error (RMSE) and a mean absolute error (MAE) are used to evaluate the accuracy of Eq. (1):

$$
\begin{aligned}
\text { RMSE } & =\sqrt{\frac{\sum_{i=1}^{n}\left(E_{c}-E_{r}\right)^{2}}{n},} \\
\text { MAE } & =\frac{\sum_{i=1}^{n}\left|E_{c}-E_{r}\right|}{n},
\end{aligned}
$$

where $E_{c}, E_{r}$, and $n$ are the radiation error given by Eq. (1), the radiation error given by the comparison experiment with the reference platform, and the total number of sampling, respectively.

From Eqs. (2) and (3), the RMSE between the radiation errors given by Eq. (1) and the radiation errors given by the comparison experiment is $0.009^{\circ} \mathrm{C}$, and the MAE is $0.007^{\circ} \mathrm{C}$. It can be inferred that the temperature sensor array may provide a possibility 
日 Radiation error given by comparison experiment with the reference platform

$\vartheta$ Radiation error given by the correction equation (1)
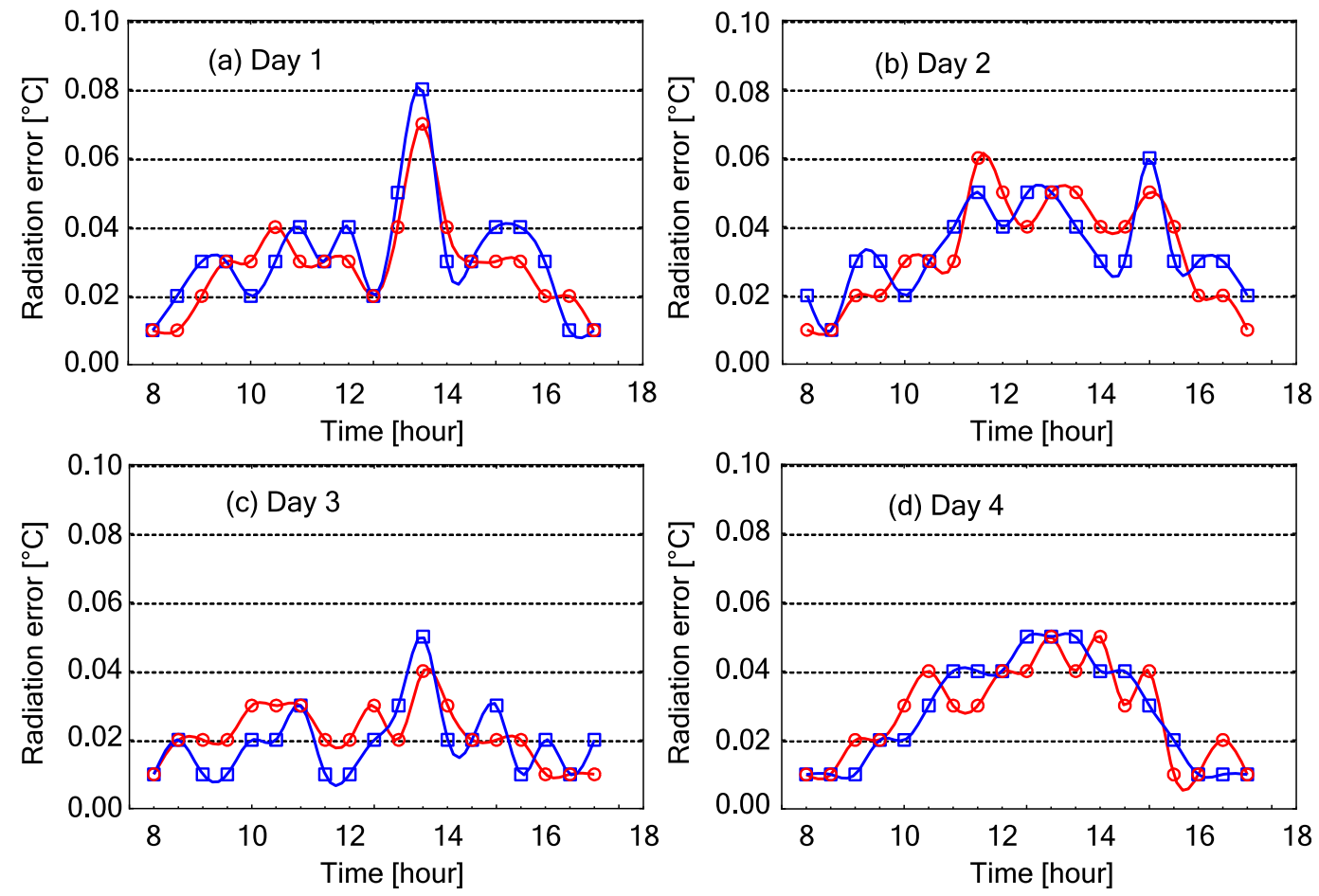

FIG. 11. Comparison between the radiation errors given by the comparison experiment with the reference platform and the radiation error given by the correction equation [Eq. (1)] at different times.

of significant improvement of the air temperature observation accuracy to the order of $0.01^{\circ} \mathrm{C}$ with the application of this radiation error correction equation.

\section{Conclusions}

In this paper, a temperature sensor array is designed. A CFD analysis of the temperature sensor arrays with different structures are performed to obtain the optimum structure of the sensor array. Then the CFD method is applied to obtain quantitative radiation errors of the sensor array. Finally, an artificial neural network model is developed to learn the relationship among the radiation error, solar radiation intensity, wind speed, sun elevation angle, reflectivity of the underlying surface, and altitude. To assess the extent to which the actual performance adheres to the theoretical CFD model and neural network model, air temperature observation experiments are conducted. The following conclusions may be obtained:

1) The radiation error of the temperature sensor array diminishes with increasing wind speed and increases with increasing solar radiation intensity, altitude, and reflectivity of the underlying surface.

2) The radiation error of the temperature sensor array is one to two orders of magnitude lower than that of the sensor equipped with a naturally ventilated radiation shield or a screen.

3) The air temperature data with significantly reduced radiation error can be obtained by using the temperature sensor array proposed in this paper, which may serve for general climate change research and other fields.

4) The air temperature observation accuracy is improved at the price of a complex structure and a complex electronic system. In addition, the sensor array requires careful maintenance. Because seven sensor probes are collaborating, even if one probe is broken, the other six help to improve the robustness of the system.

Several common underlying surfaces are considered in this paper. However, limited types of underlying surfaces may not represent situations of every weather station accurately. We will continue to study more underlying surfaces to improve the correction accuracy in 
the future. The radiation error study in the night is another complicated issue, which needs a lot of research in the future. The characteristics of the temperature sensor array may be affected by extreme weather conditions. For example, under snowstorm and freezing rain conditions, the traditional screens and radiation shields may be covered with snow or ice. Thus, the observation accuracy is compromised. The temperature sensor array proposed in this work may also be affected under these harsh weather conditions, which need further study. In addition, due to the large number of tube-shaped shields and probes, the cost of the temperature sensor array increases, which imposes a limitation of the applications of our device. Hence, reducing the cost and complexity of this device will be addressed in our future work.

Acknowledgments. We would like to express appreciation for the valuable discussions with Renhui Ding at Jiangsu Meteorological Observation Center and Li Zhang at TaiZhou Meteorological Observation Center. This work was funded by the University Natural Science Research Foundation of Jiangsu Province (Grant 18KJB530011), the Special Scientific Research Fund of Meteorological Public Welfare Profession of China (Grant GYHY200906037), the National Natural Science Foundation of China (Grants 41875035 and 41605120), the Startup Foundation for Introducing Talent of NUIST (Grant 2017r60), and the Priority Academic Program Development of Jiangsu Higher Education Institutions (Grant PAPD-III).

\section{REFERENCES}

Anderson, S. P., and M. F. Baumgartner, 1998: Radiative heating errors in naturally ventilated air temperature measurements made from buoys. J. Atmos. Oceanic Technol., 15, 157-173, https://doi.org/10.1175/1520-0426(1998)015<0157:RHEINV> 2.0.CO;2.

Dillon, M. E., W. George, and R. B. Huey, 2010: Global metabolic impacts of recent climate warming. Nature, 467, 704-706, https://doi.org/10.1038/nature09407.

Erell, E., V. Leal, and E. Maldonado, 2005: Measurement of air temperature in the presence of a large radiant flux: An assessment of passively ventilated thermometer screens. Bound.-Layer Meteor., 114, 205-231, https://doi.org/10.1007/ s10546-004-8946-8.

Fyfe, J. C., N. P. Gillett, and F. W. Zwiers, 2013: Overestimated global warming over the past 20 years. Nat. Climate Change, $\mathbf{3}$, 767-769, https://doi.org/10.1038/nclimate1972.

Georges, C., and G. Kaser, 2002: Ventilated and unventilated air temperature measurements for glacier-climate studies on a tropical high mountain site.J. Geophys. Res., 107, 4775, https:// doi.org/10.1029/2002JD002503.

Gleisner, H., P. Thejll, B. Christiansen, and J. K. Nielsen, 2015: Recent global warming hiatus dominated by low-latitude temperature trends in surface and troposphere data. Geophys. Res. Lett., 42, 510-517, https://doi.org/10.1002/2014GL062596.
Harrison, R. G., 2011: Lag-time effects on a naturally ventilated large thermometer screen. Quart. J. Roy. Meteor. Soc., 137, 402-408, https://doi.org/10.1002/qj.745.

— measurements in thermometer screens. Quart. J. Roy. Meteor. Soc., 138, 1114-1120, https://doi.org/10.1002/qj.985.

Holden, Z. A., A. E. Klene, R. F. Keefe, and G. G. Moisen, 2013: Design and evaluation of an inexpensive radiation shield for monitoring surface air temperatures. Agric. For. Meteor., 180, 281-286, https://doi.org/10.1016/j.agrformet.2013.06.011.

Hubbart, J. A., 2011: An inexpensive alternative solar radiation shield for ambient air temperature micro-sensors. J. Nat. Environ. Sci., 2, 9-14.

Hubbard, K. G., X. Lin, and E. A. Walter-Shea, 2001: The effectiveness of the ASOS, MMTS, Gill, and CRS air temperature radiation shields. J. Atmos. Oceanic Technol., 18, 851-864, https://doi.org/10.1175/1520-0426(2001)018<0851:TEOTAM > 2.0.CO;2.

Kumar, A., and M. H. Kim, 2016: CFD analysis on the thermal hydraulic performance of an SAH duct with multi V-shape roughened ribs. Energies, 9, 415, https://doi.org/10.3390/ en9060415.

Lin, X., K. G. Hubbard, and G. E. Meyer, 2001a: Airflow characteristics of commonly used temperature radiation shields. J. Atmos. Oceanic Technol., 18, 329-339, https://doi.org/ 10.1175/1520-0426(2001)018<0329:ACOCUT>2.0.CO;2.

$\longrightarrow,-$, and E. A. Walter-Shea, 2001b: Radiation loading model for evaluating air temperature errors with a non-aspirated radiation shield. Trans. ASAE, 44, 1299-1306, https://doi.org/ 10.13031/2013.6435.

,-- , and C. B. Baker, 2005: Surface air temperature records biased by snow-covered surface. Int. J. Climatol., 25, 1223 1236, https://doi.org/10.1002/joc.1184.

Lopardo, G., F. Bertiglia, S. Curci, G. Roggero, and A. Merlone, 2014: Comparative analysis of the influence of solar radiation screen ageing on temperature measurements by means of weather stations. Int. J. Climatol., 34, 1297-1310, https:// doi.org/10.1002/joc.3765.

Mahajan, R. L., B. M. Fichera, and T. W. Horst, 2005: Mechanically aspirated radiation shields: A CFD and neural network design analysis. Int. J. Heat Mass Transfer, 48, 2856-2867, https:// doi.org/10.1016/j.ijheatmasstransfer.2005.01.026.

Mozny, M., M. Trnka, P. Stepanek, Z. Zalud, V. Koznarova, L. Hajkova, D. Bares, and D. Semeradova, 2012: Long-term comparison of temperature measurements by the multi-plate shield and Czech-Slovak thermometer screen. Meteor. Z., 21, 125-133, https://doi.org/10.1127/0941-2948/2012/0355.

Preston-Thomas, H., 1990: The International Temperature Scale of 1990 (ITS-90). Metrologia, 27, 3-10, https://doi.org/10.1088/ 0026-1394/27/1/002.

Sarhan, A. R., J. Naser, and G. Brooks, 2017: CFD analysis of solid particles properties effect in three-phase flotation column. Sep. Purif. Tech., 185, 1-9, https://doi.org/10.1016/ j.seppur.2017.04.042.

Tang, D., R. N. Zhao, S. H. Wang, J. W. Wang, L. Ni, and L. Chen, 2017: The simulation and experimental research of particulate matter sensor on diesel engine with diesel particulate filter. Sens. Actuators, 259A, 160-170, https://doi.org/10.1016/ j.sna.2017.03.036.

Thomas, C. K., and A. R. Smoot, 2013: An effective, economic, aspirated radiation shield for air temperature observations and its spatial gradients. J. Atmos. Oceanic Technol., 30, 526537, https://doi.org/10.1175/JTECH-D-12-00044.1. 
van der Meulen, J. P., and T. Brandsma, 2008: Thermometer screen intercomparison in De Bilt (The Netherlands). Part I: Understanding the weather-dependent temperature differences. Int. J. Climatol., 28, 371-387, https://doi.org/10.1002/joc.1531.

Wang, F., Y. Shuai, Y. Yuan, G. Yang, and H. Tan, 2010: Thermal stress analysis of eccentric tube receiver using concentrated solar radiation. Sol. Energy, 84, 1809-1815, https://doi.org/ 10.1016/j.solener.2010.07.005.
Yang, J., Q. Liu, W. Dai, and R. Ding, 2016: Fluid dynamic design and experimental study of an aspirated temperature measurement platform used in climate observation. Rev. Sci. Instrum., 87, 084503, https://doi.org/10.1063/1.4961645.

- —, and —, 2018: A method for solar radiation error correction of temperature measured in a reinforced plastic screen for climatic data collection. Int. J. Climatol., 38, 13281336, https://doi.org/10.1002/joc.5247. 